\title{
Large scale snow water equivalent status monitoring: comparison of different snow water products in the upper Colorado Basin
}

\author{
G. A. $\operatorname{Artan}^{1}$, J. P. Verdin ${ }^{2}$, and R. Lietzow ${ }^{2}$ \\ ${ }^{1}$ ASRC Federal InuTeq LLC, US Geological Survey (USGS) Earth Resources Observation and Science (EROS) Center, \\ Sioux Falls, SD, USA \\ ${ }^{2}$ USGS Earth Resources Observation and Science (EROS) Center, Sioux Falls, SD, USA
}

Correspondence to: G. A. Artan (gartan@usgs.gov)

Received: 6 February 2013 - Published in Hydrol. Earth Syst. Sci. Discuss.: 19 March 2013

Revised: 4 November 2013 - Accepted: 19 November 2013 - Published: 18 December 2013

\begin{abstract}
We illustrate the ability to monitor the status of snow water content over large areas by using a spatially distributed snow accumulation and ablation model that uses data from a weather forecast model in the upper Colorado Basin. The model was forced with precipitation fields from the National Weather Service (NWS) Multi-sensor Precipitation Estimator (MPE) and the Tropical Rainfall Measuring Mission (TRMM) data-sets; remaining meteorological model input data were from NOAA's Global Forecast System (GFS) model output fields. The simulated snow water equivalent (SWE) was compared to SWEs from the Snow Data Assimilation System (SNODAS) and SNOwpack TELemetry system (SNOTEL) over a region of the western US that covers parts of the upper Colorado Basin. We also compared the SWE product estimated from the special sensor microwave imager (SSM/I) and scanning multichannel microwave radiometer (SMMR) to the SNODAS and SNOTEL SWE data-sets. Agreement between the spatial distributions of the simulated SWE with MPE data was high with both SNODAS and SNOTEL. Model-simulated SWE with TRMM precipitation and SWE estimated from the passive microwave imagery were not significantly correlated spatially with either SNODAS or the SNOTEL SWE. Average basin-wide SWE simulated with the MPE and the TRMM data were highly correlated with both SNODAS $(r=0.94$ and $r=0.64$; d.f. $=14-$ d.f. $=$ degrees of freedom) and SNOTEL $(r=0.93$ and $r=0.68$; d.f. $=14)$. The SWE estimated from the passive microwave imagery was significantly correlated with the SNODAS SWE $(r=0.55$, d.f. $=9, p=0.05)$ but was not significantly correlated with the SNOTEL-reported SWE values $(r=0.45$, d.f. $=9, p=0.05)$. The results indicate
\end{abstract}

the applicability of the snow energy balance model for monitoring snow water content at regional scales when coupled with meteorological data of acceptable quality. The two snow water contents from the microwave imagery (SMMR and SSM/I) and the Utah Energy Balance forced with the TRMM precipitation data were found to be unreliable sources for mapping SWE in the study area; both data sets lacked discernible variability of snow water content between sites as seen in the SNOTEL and SNODAS SWE data. This study will contribute to better understanding the adequacy of data from weather forecast models, TRMM, and microwave imagery for monitoring status of the snow water content.

\section{Introduction}

Every year large parts of the globe are seasonally covered by snow; for example, each year as much as half of the land surface in the Northern Hemisphere can be snow-covered (Robinson and Kukla, 1985). Most of the water supply for those snow-covered areas comes from snowmelt runoff (Daly et al., 2000; Schmugge et al., 2002; Tekeli et al., 2005); over $60 \%$ of the precipitation in the western US falls as snow (Serreze et al., 1999). In the upper Colorado Basin, $63 \%$ of precipitation falls as snow (Fassnacht, 2006), and 70-80\% of total annual runoff comes from snowmelt (Daly et al., 2000; Schmugge et al., 2002). In the past few decades, some basins in the US have seen historic floods that were induced and triggered from spring rain-on-snow events during years of above average winter snowfall, such as the floods of the Red River of 2009 and 2010. Monitoring the status of snowpack 
during winter and spring is important to water resources and disaster management entities.

Several methods have been used to monitor snowpack status: snow course surveys, remote sensing, and snow accumulation/ablation modeling. Worldwide, few areas have reliable ground-observed snowpack status data collected regularly on a large scale. One exception is the western US, which is monitored by the SNOwpack TELemetry system (SNOTEL). The representativeness of the snowpack characteristics estimated even from a data-extensive system such as SNOTEL is questioned by some investigators (Daly et al., 2000; Molotch and Bales, 2006).

Because of the limitations of the observational data, several snowpack status monitoring systems that rely on snowmelt models (Pan et al., 2003; Watson et al., 2006) have been described in the literature: snowmelt models combined with remotely sensed data (Cline et al., 1998), remotely sensed data combined with observed snow data (Carroll, 1995; Dressler et al., 2006), and models based solely on remote sensing methods (Bales et al., 2008; Schmugge et al., 2002; Tekeli et al., 2005). A system that utilizes assimilation of data (remotely sensed and in situ measured) and snow accumulation/ablation modeling is the NOAA National Operational Hydrologic Remote Sensing Center (NOHRC; NOHRC, 2004) Snow Data Assimilation System (SNODAS).

Efforts to monitor snowpack status for large areas from remotely sensed data have mainly focused on snow covered area (SCA) mapping (Bales et al., 2008; Kelly et al., 2003; Robinson et al., 1993; Tekeli et al., 2005); however, the snow water equivalent (SWE) status is what interests water resources and disaster risk managers the most. Despite their coarse spatial resolution and known shortcomings (Kelly et al., 2003), passive microwave sensors like the scanning multichannel microwave radiometer (SMMR) and the special sensor microwave imager (SSM/I) have gained some acceptance as tools to map SWE (Chen et al., 2001; Sun et al., 1996).

The objective of this study is to explore the possibility of monitoring the status of the snowpack at regional scales in real time with models and data that are available in even the most data-scarce regions of the globe. The recent availability of precipitation data sets estimated from satellite-based methods (Janowiak et al., 2001; Joyce et al., 2004; Xie and Arkin, 1997) and the upcoming Global Precipitation Measurement (GPM) offers an opportunity to model snow accumulation and ablation processes on regional-scales even for data-parse areas. The specific aim of our study is to investigate how SWE that is modeled (with coarse resolution meteorological data) and one that was estimated from passive microwave sensor data compared with SWE values measured by SNOTEL and estimated by SNODAS. We introduce a spatially distributed snow accumulation and ablation model that is forced with remotely sensed data and near-realtime meteorological data from forecast models. We compare model-simulated SWE with the best available regional SWE data sets. In the comparison, we include a SWE product estimated from SSM/I and SMMR to substantiate how useful they are in lieu of snowmelt-predicted SWE products. This study will contribute to a better understanding of the adequacy of data from weather forecast models, TRMM, and microwave imagery for monitoring snow water status especially in data-scarce regions of the world.

The snowmelt model we used is a spatially distributed version of the Utah Energy Balance (UEB) model (Tarboton and Luce, 1996). The UEB model has been applied successfully to several basins from different parts of the world (Koivusalo and Heikinheimo, 1999; Schulz and de Jong, 2004; Watson et al., 2006). We describe the model and data, and evaluate simulated SWE values over a region of the western US that covers parts of the upper Colorado Basin.

\section{Study site}

Figure 1 depicts the geographic extent of the study area and of the SNOTEL sites that were used in the model verification. The area $\left(43^{\circ} 48^{\prime} \mathrm{N}, 116^{\circ} 06^{\prime} \mathrm{W}\right)$ encompasses a modeling domain of $1504800 \mathrm{~km}^{2}$. The area is rugged and straddles the Continental Divide and has a mean elevation of $2203 \mathrm{~m}(\sigma=517 \mathrm{~m})$. The SNOTEL sites used for validation are mainly in the upper Colorado Basin. The average yearly precipitation that falls on the upper Colorado Basin, estimated from 39 SNOTEL stations, was $700 \mathrm{~mm}( \pm 184 \mathrm{~mm})$ for the three water years of the study - 2006, 2007, and 2008. The area has a low $(\sim 11 \%)$ tree vegetation cover.

\section{Model and data}

SWE recorded from SNODAS and SNOTEL was compared with the SWE simulated by the UEB snowmelt model and SWE estimated from microwave imagery. In the following sections, we describe the UEB snowmelt model, model input data sets, and the results of the SWE product intercomparisons. Because the SNODAS system assimilates most of the real-time recorded SWE data in the conterminous US, we assumed that the SNODAS SWE data were observed data. Although SNODAS SWE is the best regional-scale, spatially distributed SWE data available, we are not aware of a comprehensive validation of the SWE estimated by the SNODAS system. The snowmelt model was run for the period December 2005-April 2008.

\subsection{Snow accumulation and ablation model}

The UEB model (Tarboton and Luce, 1996) was used for this work. The UEB model has been applied successfully to diverse basins with good results (Koivusalo and Heikinheimo, 1999; Schulz and de Jong, 2004; Watson et al., 2006). The UEB model solves the snow energy balance at the surface 
Table 1. Snowmelt model inputs, outputs, and state variables. The input includes static distributed parameters and dynamic meteorological data.

\begin{tabular}{llll}
\hline Dynamic inputs & Static inputs & Output fluxes & State variables \\
\hline Incoming shortwave rad. & Elevation & Latent heat flux & Snow energy content \\
Incoming longwave rad. & Vegetation cover & Sensible heat flux & Snow water content \\
Air temperature & Vegetation height & Ground heat flux & Snow age \\
Average wind speed & Soil bulk density & Snow temperature & \\
Precipitation & & Melt advected energy & \\
Relative humidity & & Melt outflow flux & \\
Atmospheric pressure & & & \\
\hline
\end{tabular}

by means of three state variables (snow water equivalence, snow water content, and the age of the snow surface) using a lumped representation of the snowpack as a single layer. Table 1 lists input, output, and model state variables. By using spatially distributed meteorological fields, we assumed that we would be able to account for the snow cover heterogeneity component caused by the variability of the precipitation and solar radiation fields.

For model parameters, we kept the values of the UEB model parameters from Tarboton and Luce (1996) unchanged, except for the snow density, which was changed from 450 to $320 \mathrm{~kg} \mathrm{~m}^{-3}$ - a value that is more appropriate for the study area (Josberger et al., 1996; Molotch and Bales, 2005). To estimate model parameters, Tarboton and Luce (1996) have a calibration data set from the Central Sierra Snow Laboratory collected in the winter of 19851986. Even though the model has snow redistribution capability, there is no straightforward way to determine appropriate drift factor for every modeling grid. Besides, the sizes of our modeling grids $\left(0.05^{\circ} \times 0.05^{\circ}\right.$ and $\left.0.1^{\circ} \times 0.1^{\circ}\right)$ do not warrant modeling snow redistribution processes that usually take place at smaller scales. Therefore, snow redistribution was not taken into account in the simulation results that are presented here.

\subsection{Data}

The snow energy balance model was run with inputs of air temperature, precipitation, wind speed, humidity, and radiation (longwave and shortwave) with a temporal resolution of $6 \mathrm{~h}$ time steps and spatial resolutions of $0.05^{\circ} \times 0.05^{\circ}$ and $0.1^{\circ} \times 0.1^{\circ}$ (about 5 and $10 \mathrm{~km}$ ). Six hours is the maximum time step that is sufficient to resolve the solar diurnal cycle (Tarboton and Luce, 1996). Precipitation is the most important meteorological model input variable. The precipitation data used for the $0.05^{\circ}$ modeling resolution was the National Weather Service (NWS) regional River Forecast Centers (RFCs)'s Multi-sensor Precipitation Estimator (MPE) data set, where the precipitation input for the $0.1^{\circ}$ resolution runs was the TRMM precipitation estimates. In the subsequent paragraphs, we describe model input meteorological data and the data that were used to test simulated SWE ability to monitor the snowpack water content through the season. Table 1 summarizes the data.

\subsubsection{Meteorological data from weather forecast model}

The air temperature $\left(T_{\mathrm{a}}\right)$, relative humidity $(\mathrm{RH})$, direct and diffuse solar radiation $\left(R_{\mathrm{S}}\right)$, and wind speed $(U)$ were from the NOAA Global Forecast System (GFS) model. To match the MPE resolution; the $T_{\mathrm{a}}$, RH, and $R_{\mathrm{S}}$ were downscaled from their original $0.375^{\circ}$ resolution grid to a $0.05^{\circ}$ resolution grid. The downscaling algorithms rely on the topographic data to downscale the coarse weather forecasting model's output fields to the higher resolution. To downscale the three variables, terrain geomorphometric characteristics (aspect, slope, and sky-view factor) calculated from a digital elevation model (DEM) were utilized. To redistribute the solar radiation, we used the algorithms of Dozier and Frew (1990) and Dubayah and Van Katwijk (1992). $T_{\mathrm{a}}$ was downscaled with a moist adiabatic lapse rate model (Stone and Carlson, 1979), and RH was downscaled with the reestimated $T_{\mathrm{a}}$.

\subsubsection{Multi-sensor Precipitation Estimator (MPE)}

The MPE data are made by combining data from rain gages, radars, and satellite sensors. The original format of MPE data is in the Hydrologic Rainfall Analysis Project (HRAP) grid format and has an approximate spatial resolution of $4 \mathrm{~km}$. Since the radar coverage of the mountainous areas of the western US is poor (Wood et al., 2003), especially during the winter, the MPE product west of the Continental Divide is mainly made from gage reports and long-term climatologic precipitation data (PRISM). The MPE has been operational since 2002, but only data from 2005 were available for download from NOAA's website at http://water.weather. gov/precip/download.php.

\subsubsection{Tropical Rainfall Measuring Mission (TRMM)}

We used TRMM precipitation data from the 3B42RT product at a $0.25^{\circ}$ spatial resolution (Tian et al., 2007). The 3B42RT product is made by the combination of precipitation estimates from the TRMM microwave and infrared (IR) sensors. 
Table 2. Locations of the SNOTEL station where simulated SWE and MI-estimated SWE were validated.

\begin{tabular}{|c|c|c|c|c|}
\hline $\begin{array}{l}\text { Station } \\
\text { ID }\end{array}$ & Station name & Lat & Long & Elevation \\
\hline 1 & Brumley & 39.08 & -106.53 & 3231 \\
\hline 2 & Columbine Pass & 38.42 & -108.37 & 2865 \\
\hline 3 & Elk River & 40.83 & -106.97 & 2652 \\
\hline 4 & Lost Dog & 40.80 & -106.73 & 2841 \\
\hline 5 & Mccoy Park & 39.60 & -106.53 & 2890 \\
\hline 6 & Middle Fork Camp & 39.78 & -106.02 & 2725 \\
\hline 7 & Park Cone & 39.82 & -106.58 & 2926 \\
\hline 8 & Park Reservoir & 39.03 & -107.87 & 3036 \\
\hline 9 & Lone Cone & 37.88 & -108.18 & 2926 \\
\hline 10 & Elkhart Park & 43.00 & -109.75 & 2865 \\
\hline 11 & Battle Mountain & 41.03 & -107.25 & 2268 \\
\hline 12 & New Fork Lake & 43.12 & -109.93 & 2542 \\
\hline 13 & East Rim Divide & 43.13 & -110.20 & 2417 \\
\hline 14 & Sandstone $R_{\mathrm{S}}$ & 41.12 & -107.17 & 2484 \\
\hline 15 & Hickerson Park & 40.90 & -109.95 & 2787 \\
\hline 16 & Trout Creek & 40.73 & -109.67 & 2901 \\
\hline 17 & Mosby Mtn & 40.60 & -109.88 & 2899 \\
\hline 18 & Lakefork \#1 & 40.58 & -110.43 & 3174 \\
\hline 19 & Loomis Park & 43.17 & -110.13 & 2512 \\
\hline 20 & Snider Basin & 42.48 & -110.52 & 2457 \\
\hline 21 & Kelley R. S. & 42.27 & -110.8 & 2493 \\
\hline 22 & Burro Mountain & 39.87 & -107.58 & 2865 \\
\hline 23 & Hams Fork & 42.15 & -110.67 & 2390 \\
\hline 24 & King's Cabin & 40.70 & -109.53 & 2659 \\
\hline 25 & Lasal Mountain & 38.47 & -109.27 & 2914 \\
\hline 26 & Porphyry Creek & 38.48 & -106.33 & 3280 \\
\hline 27 & Slumgullion & 37.98 & -107.20 & 3487 \\
\hline 28 & Butte & 38.88 & -106.95 & 3097 \\
\hline 29 & Dry Lake & 40.53 & -106.77 & 2560 \\
\hline 30 & Gunsight Pass & 43.37 & -109.87 & 2993 \\
\hline 31 & Kendall R. S. & 43.23 & -110.02 & 2359 \\
\hline 32 & Stillwater Creek & 40.22 & -105.92 & 2658 \\
\hline 33 & Rock Creek & 40.53 & -110.68 & 2405 \\
\hline 34 & Indian Creek & 42.30 & -110.67 & 2873 \\
\hline 35 & Lizard Head Pass & 37.78 & -107.92 & 3109 \\
\hline 36 & Spring Creek Divide & 42.52 & -110.65 & 2743 \\
\hline 37 & El Diente Peak & 37.78 & -108.02 & 3048 \\
\hline 38 & Townsend Creek & 42.68 & -108.88 & 2652 \\
\hline 39 & McClure Pass & 39.12 & -107.28 & 2896 \\
\hline
\end{tabular}

The microwave sensor provides the main estimates, and the IR sensors provide coverage for areas with gaps in the microwave precipitation estimates. Although the TRMM 3B42 estimates are considered better than the 3B42RT product, the $3 \mathrm{~B} 42$ is not available in real time as the $3 \mathrm{~B} 42 \mathrm{RT}$ product is. The 3B42RT products are usually posted to the TRMM Web site about $6 \mathrm{~h}$ after the event.

\subsubsection{SWE from the microwave imagers}

The SWE data sets estimated by microwave imagers that we used are from the Global Monthly EASE-Grid SWE Climatology (Armstrong et al., 2007). The EASE-Grid SWE data

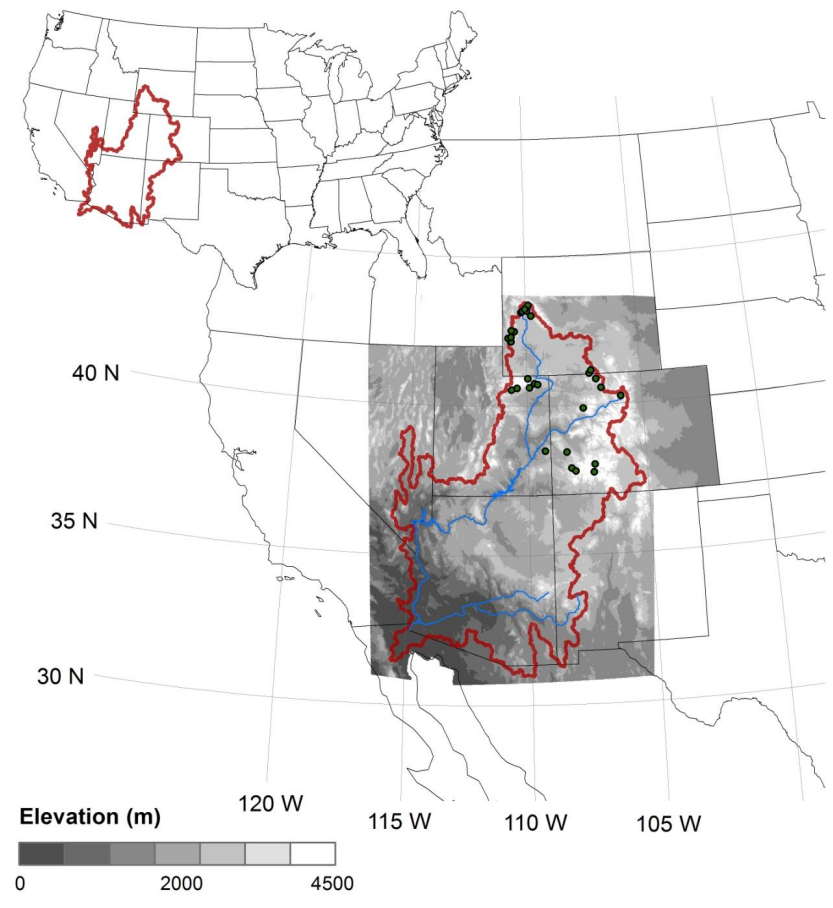

Fig. 1. A shaded relief map of the study area and locations of the SNOTEL sites with an outline of the Colorado Basin and western US states.

sets are monthly average values downloaded from the $\mathrm{Na}$ tional Snow and Ice Data Center Distributed Active Archive Center (NSIDC, http://nsidc.org/data/), University of Colorado at Boulder. The data are derived from the SMMR and selected SSM/Is. The EASE-Grid SWE data sets have a resolution of $25 \mathrm{~km}$, about $0.25^{\circ}$, but since the SSM/I data used to produce the SWE are 19 and $37 \mathrm{GHz}$ (the $19 \mathrm{GHz}$ imagery has a footprint of $69 \mathrm{~km} \times 43 \mathrm{~km}$ ), the actual resolution of the SWE could be coarser than the nominal $25 \mathrm{~km}$. The microwave-based SWE (MI SWE) spans from December 2005 to April 2007. Only data from December to April were used in the intercomparison with the other SWE products.

\subsubsection{SNOTEL}

SNOTEL is an automated network of stations that record snow and meteorological variables in the western US and Alaska. SNOTEL is a Natural Resources Conservation Service (NRCS) network. Most SNOTEL sites are located at higher elevations. We downloaded SWE, precipitation, and air temperature data from the NRCS's website (http://www. wcc.nrcs.usda.gov/snow). The data were recorded at 39 stations located in the areas shown in Fig. 1 for the period October 2005-September 2008 and summarized in Table 2. 
Table 3. Source and resolution of meteorological and snow data.

\begin{tabular}{lllll}
\hline \multirow{2}{*}{ Data } & Source & \multicolumn{2}{c}{ Resolution } & \multirow{2}{*}{ Downscaling } \\
\cline { 3 - 4 } & & Spatial & Temporal & \\
\hline$T_{\mathrm{a}}, \mathrm{RH}, R_{\mathrm{S}}, U$ & NOAA's GFS Model & $0.375^{\circ} \times 0.375^{\circ}$ & $6 \mathrm{~h}$ & $0.05^{\circ}, 0.1^{\circ}$ \\
$\mathrm{MPE}$ & NWS RFCs & $4 \mathrm{~km} \times 4 \mathrm{~km}$ & $24 \mathrm{~h}$ & $0.05^{\circ}, 0.1^{\circ}$ \\
$\mathrm{TRMM}$ & NASA & $0.25^{\circ} \times 0.25^{\circ}$ & $3 \mathrm{~h}$ & $0.1^{\circ}$ \\
SWE (EASE-Grid) & NSIDC & $0.25^{\circ} \times 0.25^{\circ}$ & $24 \mathrm{~h}$ & none \\
SWE,$T_{\mathrm{a}}$ & SNOTEL & Point data & $24 \mathrm{~h}$ & none \\
SWE (SNODAS) & NOAA NOHRC & $1 \mathrm{~km} \times 1 \mathrm{~km}$ & $24 \mathrm{~h}$ & $0.05^{\circ}$ \\
\hline
\end{tabular}

\subsubsection{SNODAS}

SNODAS is an NOAA NOHRC SWE data set (NOHRC, 2004). SNODAS is made by the assimilation of modeled SWE, remotely sensed SWE, and station-recorded SWE data. The SNODAS data set covers the conterminous US at $1 \mathrm{~km}$ spatial resolution and $24 \mathrm{~h}$ temporal resolution. Although we will consider hereafter the SWE as observed, we are not aware of any extensive validation done on the SNODAS SWE data sets. Because SNODAS assimilates all available observed snow data, it is difficult to validate the accuracy of the SNODAS product. Nevertheless, SNODAS has been used in several research studies and is the only publicly available large-scale SWE product. SNODAS data sets were downloaded from the NSIDC website (http://nsidc.org/ data). Before comparing SNODAS with other data sets, the SNODAS data were re-gridded to $0.05,0.1$, and $0.25^{\circ}$ resolution from the native $1 \mathrm{~km}$ resolution. Table 3 summarizes the spatial and temporal resolutions of the meteorological and snow data that were used in this study.

\subsection{Performance indicators}

For performance indicators, we used the percent of bias, coefficient of determination, total root mean square error (RMSE), and parameters that are based on the RMSE outlined by Willmott (1982). Willmott (1982) decomposed the RMSE into the systematic error (RMSEs), which can be reduced with small improvements in model parameters and input data, and unsystematic RMSE (RMSEu), which cannot be reduced without extensive changes in the model structure and input data. The RMSE, RMSEs, and RMSEu parameters are defined (Willmott, 1982) as

RMSE $=\left[\frac{1}{n} \sum_{i=1}^{n}\left(P_{i}-O_{i}\right)^{2}\right]^{1 / 2}$,
RMSEs $=\left[\frac{1}{n} \sum_{i=1}^{n}\left(\hat{P}_{i}-O_{i}\right)^{2}\right]^{1 / 2}$,
RMSEu $=\left[\frac{1}{n} \sum_{i=1}^{n}\left(\hat{P}_{i}-P_{i}\right)^{2}\right]^{1 / 2}$,

$$
\begin{aligned}
& \text { RMSEs }=\left[\frac{1}{n} \sum_{i=1}^{n}\left(\hat{P}_{i}-O_{i}\right)^{2}\right]^{1 / 2}, \\
& \text { RMSEu }=\left[\frac{1}{n} \sum_{i=1}^{n}\left(\hat{P}_{i}-P_{i}\right)^{2}\right]^{1 / 2},
\end{aligned}
$$

where $n$ is the number of observations, $O_{i}$ is the observed value, $P_{i}$ is the predicted value, and $\hat{P}_{i}=a \cdot O_{i}+b$. To describe how much the model underestimates or overestimates the variable of interest, the percent bias was calculated according to

$$
\operatorname{Bias}=100 \cdot \frac{\sum_{i=1}^{n} P_{i}-\sum_{i=1}^{n} O_{i}}{\sum_{i=1}^{n} O_{i}} .
$$

\section{Results and discussion}

\subsection{Snowmelt model meteorological inputs}

We tested the precipitation values reported by MPE and TRMM by comparing them to the precipitation values recorded at the 39 SNOTEL stations shown in Fig. 1. By comparing gridded data of varying spatial scales and point data, there should not be an expectation of perfect agreement even if both data are correct. We compared precipitation totals accumulated in the snow accumulation/ablation periods of the three years of the simulation period - 1 January 200630 April 2006, 1 January 2007-30 April 2007, and 1 January 2008-28 April 2008 (d.f. = 115). Both MPE and TRMM were negatively biased against SNOTEL precipitation as illustrated in Fig. 2; on average the percent bias of the MPE per season for the 39 locations was $-26 \%$ with a mean and standard deviation of $-84 \pm 110 \mathrm{~mm}$, and for the TRMM the bias was $-51 \%(-164 \pm 124 \mathrm{~mm})$. The correlation between the MPE and TRMM was even lower than the one the two data sets had with SNOTEL data $(r=0.53)$. Higher proportions of the precipitation differences with SNOTEL sets were systematic errors for both the TRMM (86\% of RMSE) and the MPE data sets (77\% of RMSE), which means the data could be improved with simpler correction schemes.

The large discrepancy of the MPE compared with SNOTEL is difficult to explain even when the perils of comparing gridded precipitation with values from a single gage are taken into account. The discrepancies could be due to the difference between the methods used to calculate the MPE values east and west of the Continental Divide. The large 


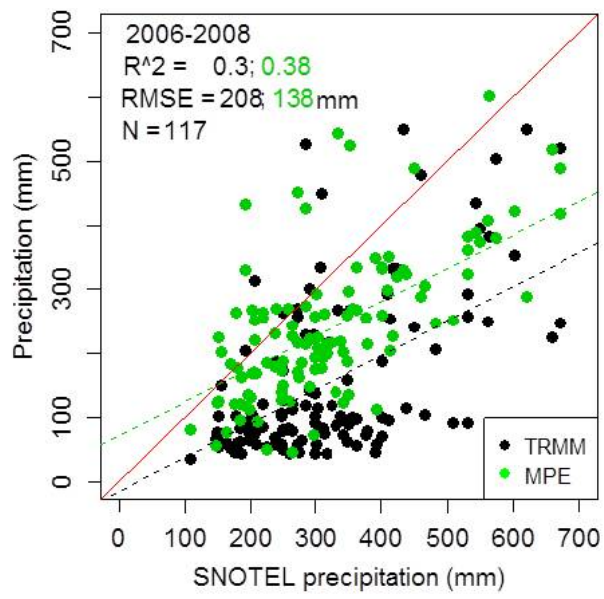

Fig. 2. Scatterplots of the total precipitation recorded at 39 SNOTEL sites for the periods of 1 January 2006-30 April 2006, 1 January 2007-30 April 2007, and 1 January 2008-28 April 2008 compared with precipitation estimates for the same locations from MPE (black) and TRMM (green).

magnitude of the discrepancy between some of the SNOTEL station-recorded precipitation and the MPE suggests that the MPE estimation needs to be improved. Our results on the bias direction, being inclined for underestimation, are in line with what Habib et al. (2009) observed when they weighted precipitation values from MPE against rain-gage-recorded precipitation.

The GFS daily mean $T_{\mathrm{a}}$ extracted from grid-cells was compared to SNOTEL-recorded $T_{\mathrm{a}}$ from the 39 stations. The GFS $T_{\mathrm{a}}$ was created by averaging four $6 \mathrm{~h} T_{\mathrm{a}}$. The comparison period was the same as the precipitation evaluation period - winter and spring - when the $T_{\mathrm{a}}$ influences the snow process. The elevation at the 39 sites ranges from 2268 to $3487 \mathrm{~m}$. Figure 3 shows the plots of the average daily GFSand SNOTEL-recorded $T_{\mathrm{a}}$ for the 39 sites for the three seasons. GFS $T_{\mathrm{a}}$ seasonally matches the SNOTEL-recorded $T_{\mathrm{a}}$ (Fig. 3). The $T_{\mathrm{a}}$ of both GFS and SNOTEL were significantly correlated $\left(R^{2}=0.61\right.$, d.f. $\left.=171\right)$, but the GFS $T_{\mathrm{a}}$ were negatively biased versus the $T_{\mathrm{a}}$ recorded at the SNOTEL sites. The bias between GFS and SNOTEL $T_{\mathrm{a}}$ was not correlated with elevation (Fig. 4). The negative bias of the GFS $T_{\mathrm{a}}$ is counterintuitive given that the SNOTEL sites are usually located at higher elevations than the surrounding terrain. The presence of a negative bias within all elevation bands suggests that the elevation correction applied to the original GFS data was not the cause of the biases, but a systematic GFS underestimation bias. Others have reported similar results of negative biases of weather forecast model air temperature in the western US during the winter months (Pan et al., 2003).

\subsection{Spatial intercomparisons of the SWE data sets}

The SWE grids simulated with the UEB model and the SWE grids estimated from MI were compared against SWE from SNOTEL and SNODAS. While the SWE from the UEB simulations and the SNODAS system had only a few grids with missing data (grids over water bodies), the SWE estimated from the MI data sets has a high number of pixels with missing data. For example, MI-estimated SWE had missing data in $40 \%$ of the area for February 2007 (Fig. 5). The evaluation of the SWE was done at the grids corresponding with the sites of the 39 SNOTEL sites shown in Fig. 1. The SNODAS grids used in the comparisons were upscaled from their native $1 \mathrm{~km}\left(\sim 0.01^{\circ}\right)$ resolution to grids with 0.05 , 0.10 , and $0.025^{\circ}$ resolution. Statistical indexes (correlation coefficients, percent biases, RMSE, RMSEs, and RMSEu) were calculated at each of the 39 validation sites between the SNODAS SWE and MI- and UEB-produced SWE. Additionally, to give a contextual frame-of-reference, the SWE products were compared to the SWE recorded at the 39 sites by the SNOTEL system.

The average monthly SWE value recorded at the SNOTEL sites was $259 \pm 96 \mathrm{~mm}$ (mean \pm standard deviation) and $240 \pm 98 \mathrm{~mm}$ for the periods January 2006-April 2008 (UEB simulations period) and January 2006-April 2007 (the period where MI-estimated SWE was available), respectively. Of the 39 sites, the SWEs simulated with the UEB were significantly correlated with the SNODAS SWE $(p=0.05)$ in 38 and 25 sites for the MPE and TRMM precipitation, respectively (Fig. 7a). The SWE estimated from MI was not significantly correlated $(p=0.05)$ with the SNODAS SWE at 12 sites (Fig. 7a). The correlation between the SWE products and the SNOTEL recorded SWE was significant at 39, 27, and 2 sites for the UEB-MPE, UEB-TRMM, and MISWE products, respectively (Fig. 7b).

Figure 8a-f shows linear and box plots of the three SWE products contrasted with concurrent SNOTEL and SNODAS SWE. The MI-estimated SWE consistently underestimates the SWE depicted by the SNODAS or the SNOTEL (Fig. 8c). The SWE simulated with the UEB model forced with TRMM data for precipitation also consistently underpredicted the SWE most of the time (Fig. 8b). The SWE modeled with UEB driven with the MPE data was in good agreement with the SNODAS and SNOTEL SWE values, except for one location that had an extremely large SWE value (Fig. 8d).

Given the large difference in precipitation and elevation between the sites, it is fair to expect that SWE would vary greatly between sites. Accumulated precipitation recorded by the SNOTEL network at 39 sites for the snowmelt/accumulation months of 2006-2008 ranged from 109 to $826 \mathrm{~mm}$. The SWE simulated with the TRMM precipitation (Fig. 7e) and MI-estimated SWE had a much narrower interquartile range than the SWE simulated with MPE (Fig. 8f). The process of upscaling by itself narrows the interquartile range as shown by the SNODAS data (Fig. 8d 
Table 4. Statistical summary of the comparison between the SWE products and the SNOTEL data sets. The last row is the statistics summary of comparison between the $0.05^{\circ}$ resolution SNODAS and the point SNOTEL SWE.

\begin{tabular}{lrcrrrc}
\hline Data set & Mean $\pm \sigma$ & $r^{2}$ & Bias & RMSE & RMSEs & RMSEu \\
\hline Microwave & $47 \pm 33$ & 0.20 & $-167 \%$ & 184 & 182 & 28 \\
UEB-TRMM & $53 \pm 57$ & 0.46 & $-186 \%$ & 203 & 199 & 41 \\
UEB-MPE & $146 \pm 75$ & 0.87 & $-37 \%$ & 107 & 102 & 32 \\
SNODAS & $202 \pm 98$ & 0.96 & $-37 \%$ & 43 & 39 & 18 \\
\hline
\end{tabular}

Table 5. Statistical summary of the evaluation of SWE products compared to the SNODAS product. The SNODAS product compared to each product had the spatial and temporal resolution as the products $\left(0.05,0.10\right.$, and $0.25^{\circ}$ resolution; daily or monthly).

\begin{tabular}{lrcrrrc}
\hline Data set & Mean $\pm \sigma$ & $r^{2}$ & Bias & RMSE & RMSEs & RMSEu \\
\hline Microwave & $47 \pm 33$ & 0.30 & -59 & 100 & 97 & 26 \\
UEB-TRMM & $53 \pm 57$ & 0.58 & -137 & 154 & 150 & 36 \\
UEB-MPE & $146 \pm 75$ & 0.89 & -56 & 67 & 62 & 24 \\
\hline
\end{tabular}

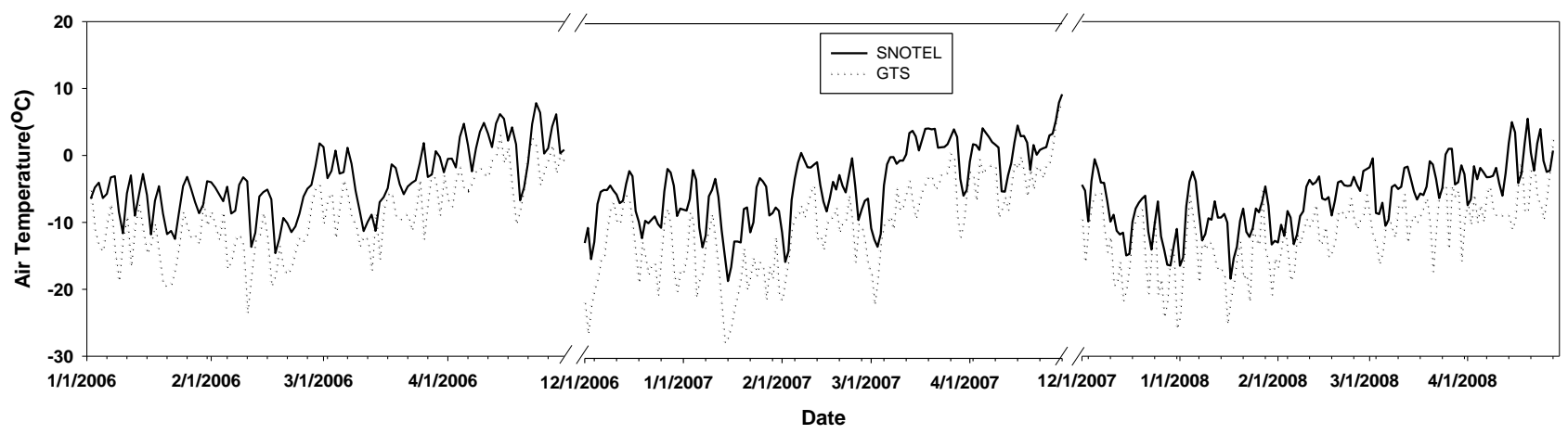

Fig. 3. Average daily forecasted GFS air temperature (dotted) and SNOTEL-recorded daily average temperature (solid line) at the 39 SNOTEL sites. GFS's air temperatures were extracted from $0.05^{\circ}$ resolution grids and an average of the 06:00, 12:00, 18:00 UTC, and the following day 00:00 UTC forecasts.

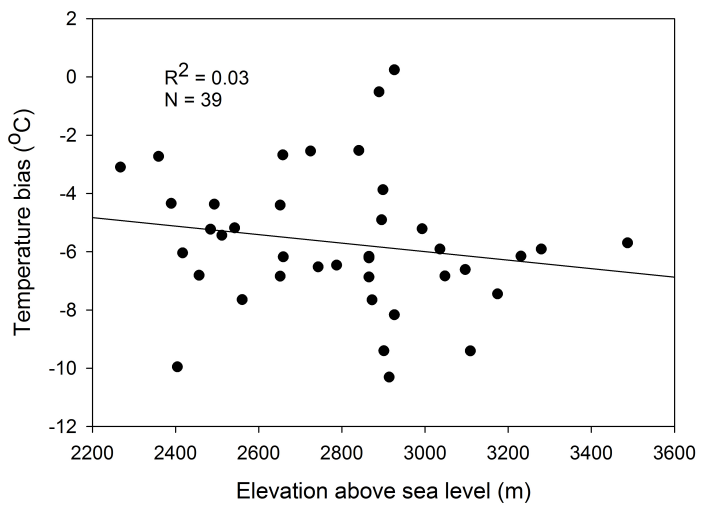

Fig. 4. Bias of the GFS average daily air temperature from the air temperature recorded at the SNOTEL sites and the sites' elevations. and $\mathrm{f}$ ). We think that the lower variability of the TRMMsimulated SWE was in part due to the sub-optimal model grid resolution for modeling the snow accumulation/ablation processes in the study area (Artan et al., 2000; Blöschl, 1999) and the low accuracy of the TRMM 3B42RT product (see Fig. 2).

Tables 4 and 5 summarize the statistical indices of the SWE comparisons. Of the three SWE products, the SWE simulated with UEB when forced with NOAA's MPE precipitation was the best performer. The TRMM-simulated SWE and MI-estimated SWE are not adept as site specific snowpack monitoring tools.

Figure 8a-f shows the relationship between the elevation and the correlations the SNODAS-estimated SWE has with the SWE predicted from the UEB or the SWE estimated from the MI imagery. The MI-estimated SWE products have a significant negative correlation $(r=-0.45$, d.f. $=37, p<0.05)$ with the elevation value of the sites, but neither of the two SWE simulated with UEB exhibited any relationship with elevation (Fig. $8 \mathrm{~b}$ and c). The MI provides better prediction of 


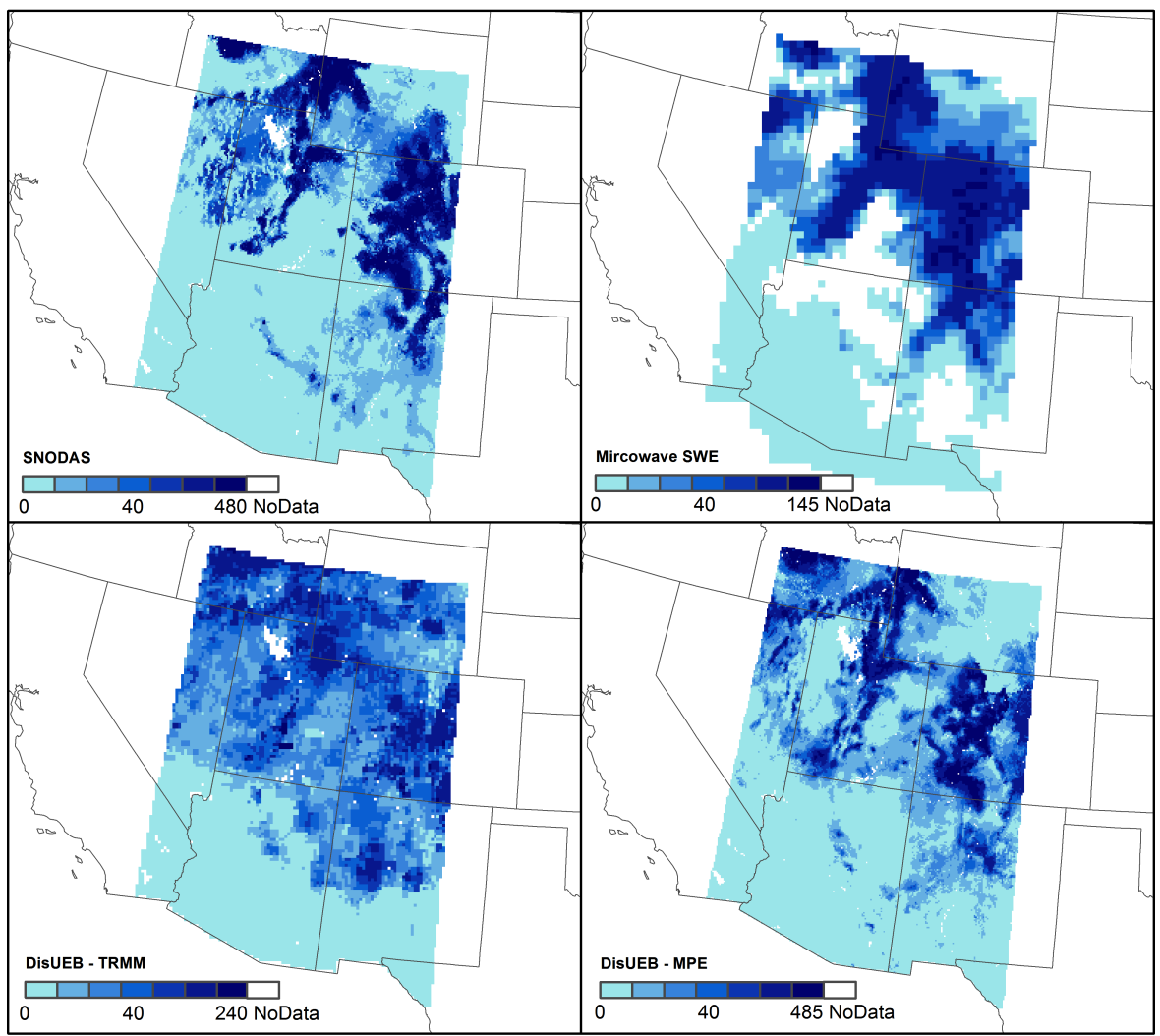

Fig. 5. Average SWE for February 2007 predicted with the distributed UEB model, microwave imagery, and SNODAS. Over $40 \%$ of the area had missing data for the SWE data set estimates from the microwave imagery.
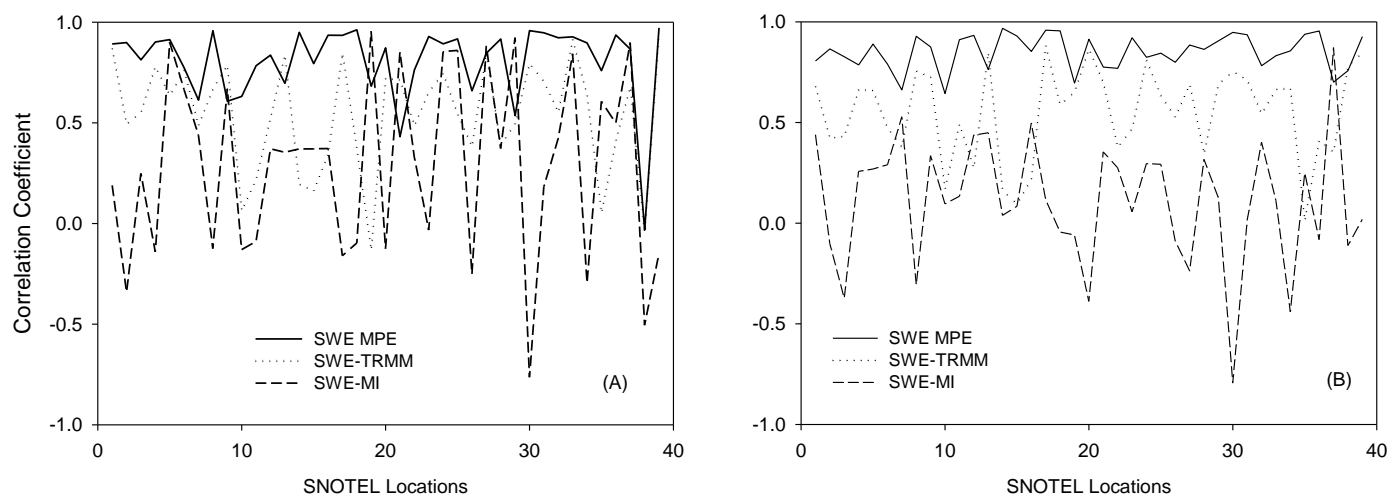

Fig. 6. Correlation coefficients between the average seasonal (A) SNODAS SWE at various grid resolutions and (B) the SWE recorded by the SNOTEL site at 39 sites in the upper Colorado Basin with the SWE estimate products from the MI imagery and UEB simulations.

SWE at lower elevation terrains. All three SWE products had the lowest skills in the southwestern part of the study area.

Among the three SWE data sets we evaluated to reproduce SWE values seen in the SNODAS and SNOTEL data sets, the performance of the MI-estimated SWE was the worst in most of the correlation metrics. The MI SWE had the lowest correlation with the SNODAS and SNOTEL SWE. Both the MI - estimated SWE and UEB-TRMM - simulated SWE had relatively large systematic errors. Both products also lack the ability to differentiate sites with high snowfall from sites with small snowpack (see Fig. 7b and d). Furthermore, the skills of the MI-estimated SWE to reproduce the values recorded by SNOTEL and SNODAS were negatively correlated with the elevation. Other researchers have also reached similar conclusions on the poor performance of MI-estimated SWE for the mountainous western US; for example, Dong et al. (2005) found that in the western US, the complex nature of the terrain and climate causes a significant error in the estimation of 

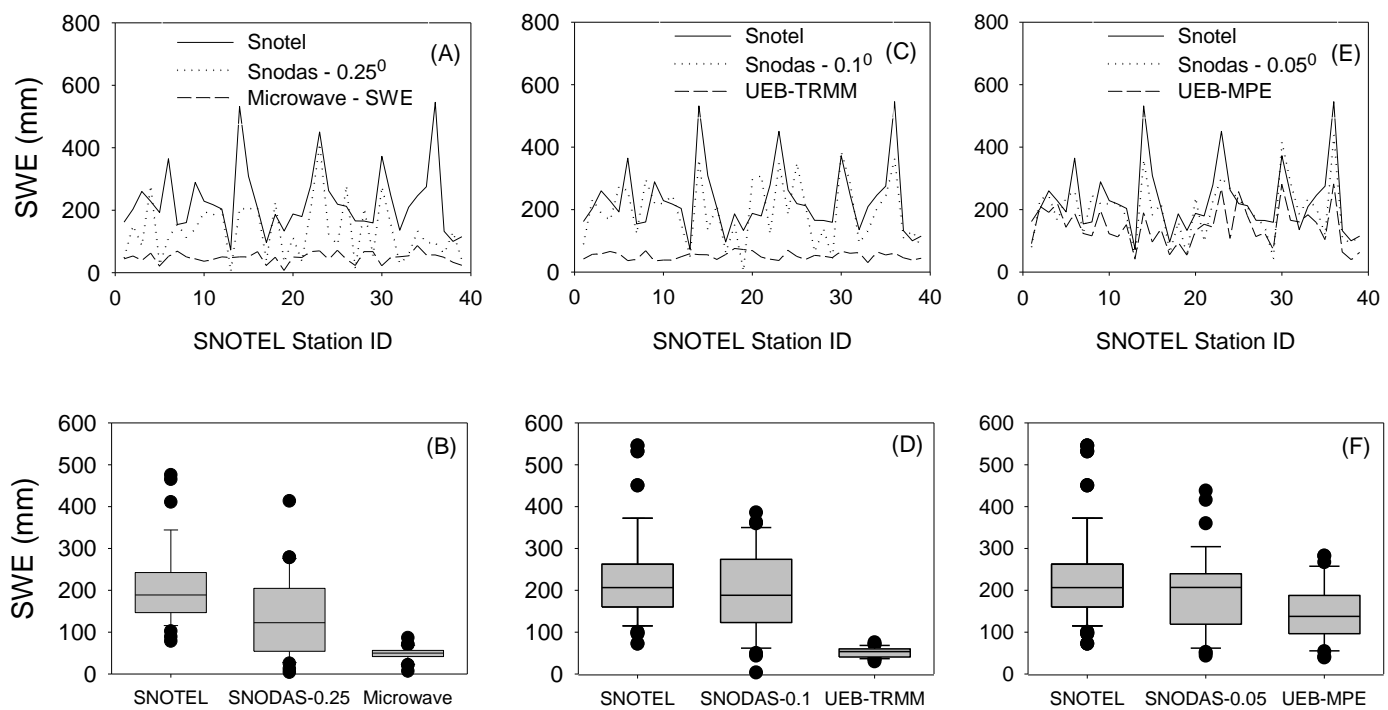

Fig. 7. Average SWE from SNOTEL and SNODAS for the winter and spring months compared with SWE estimated from (A) MI, (C) SWE predicted with UEB when driven with TRMM precipitation, and (E) UEB forced with MPE precipitation. The SWE simulated with the UEB is for the period January 2006-April 2008, excluding the months from June to November. (B, D, F) are box plots of the data in the first three graphs.
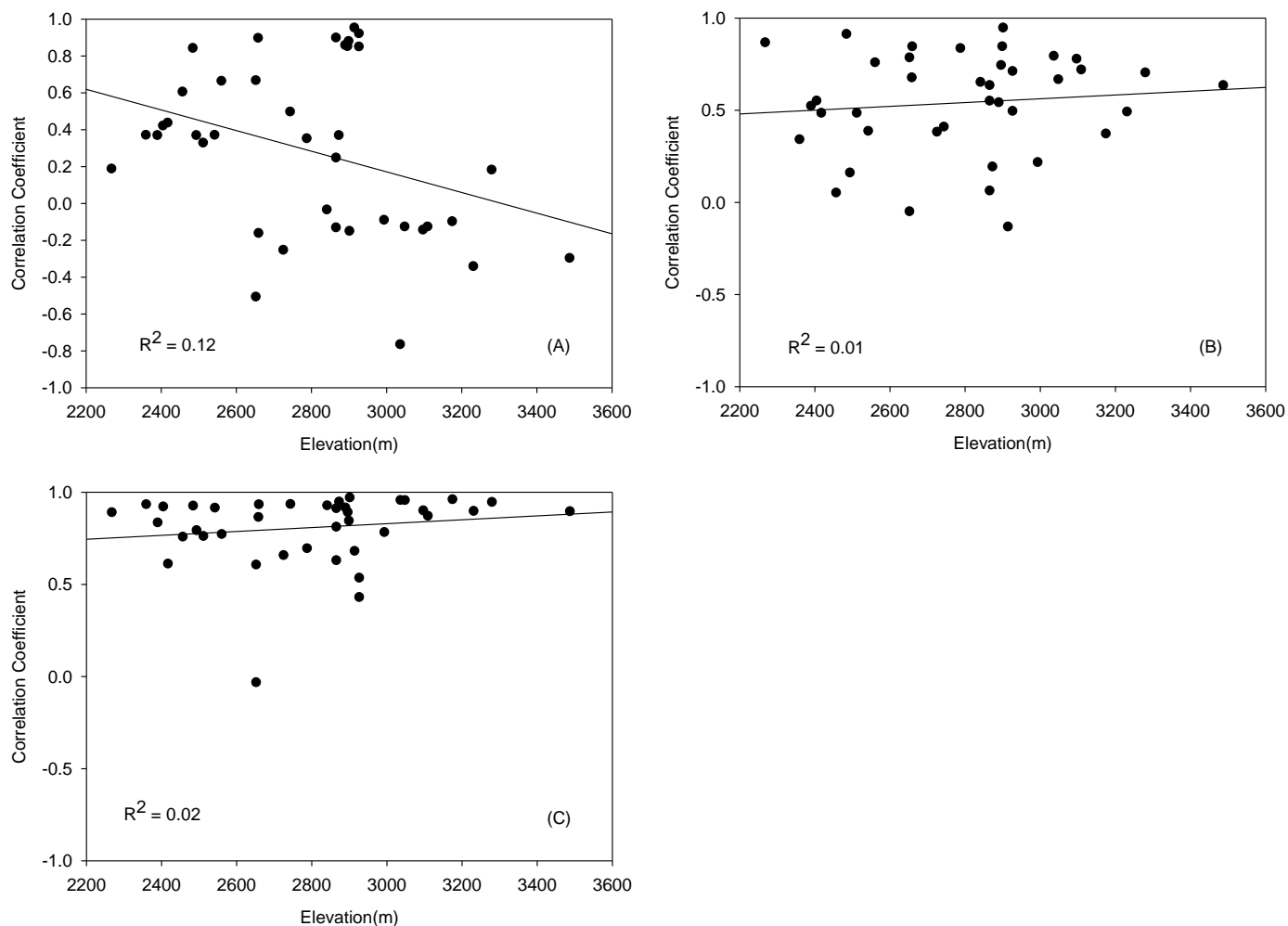

Fig. 8. Relationships between elevations and correlation between the three SWE products and SNODAS SWE plotted at the SNOTEL sites. Correlation of the SWE estimated from microwave imagers (A), correlation of the SWE simulated with UEB forced with TRMM precipitation data (B), and SWE simulated with the UEB with MPE as input precipitation data set (C). 

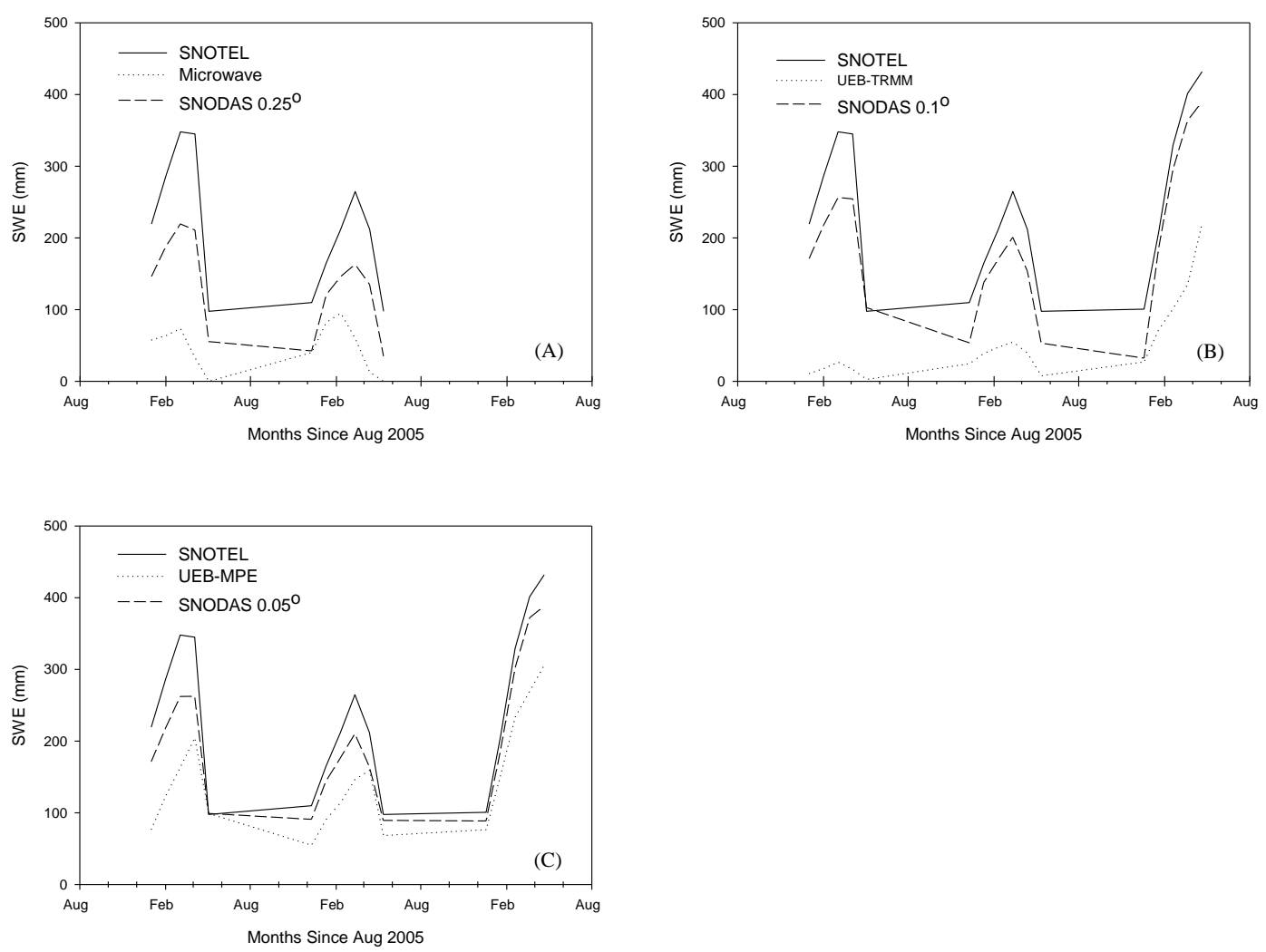

Fig. 9. Time series plots of averaged SWE (at the 39 SNOTEL sites) from SNOTEL and SNODAS and (A) the microwave imagers, (B) simulated with the UEB model with TRMM precipitation, and (C) modeled with UEB model and MPE precipitation.

SWE from microwave imagery. The low random error component, once the sources of the errors are fully known, should make possible the improvement of the UEB-TRMM and Miestimated SWE product.

\subsection{Temporal intercomparisons of the SWE data sets}

The average SWE value at the 39 SNOTEL sites was calculated at every time step (16 months of data for all products except the MI-estimated SWE, which only had 11 months of data available) for the simulated and observed SWE data sets. Figure $9 \mathrm{a}-\mathrm{c}$ shows the time series plots of the evolution through the season of the average SWE in the study area from SNOTEL, SNODAS, estimated from MI, and simulated by the UEB. All of the SWE products displayed a similar evaluation of the SWE temporal pattern. The SWE estimated from the MI showed (Fig. 9a) an earlier start of the melt season than either SNODAS or SNOTEL, but the snowpack simulated with the UEB model (Fig. 9b and c) showed a later start of the melt season than SNODAS. Although the SWE estimated from the MI has a monthly time step that makes it difficult to accurately quantify the exact date of the start of the melt season, prediction of the start of the melt season of one month earlier by the MI will decrease the usefulness of the SWE-MI product for monitoring purposes. The SNODAS
SWE start of the melt period for two seasons (2005/2006 and 2006/2007) was about two weeks earlier than SNOTEL's.

Figure $10 \mathrm{a}-\mathrm{d}$ presents the linear relationships between the average monthly values of the SWE products. The SWE estimated from the MI was not significantly correlated with the SNODAS SWE (Fig. 10a). But the SWE simulated with the UEB models was in good agreement with the SNODASestimated SWE (Fig. 10b and c) with a clear linear relationship. The UEB-MPE-simulated SWE mostly captured the SNODAS SWE evolution through the season. Figure 10d shows the average area-wide SWE from the SNODAS and SNOTEL data sets. The striking feature of Fig. 10d is the great agreement between the two products in the three years of the comparison (16 months).

The later start of the melt season seen in the plots of UEBsimulated SWE (Fig. 9b and c) was due to the negative bias seen in model input air temperature (Fig. 4) and elucidates the effects of the errors in the input meteorological data on the UEB-simulated SWE. To investigate the influence of the bias of the input air temperature, we re-ran the UEB-MPE by increasing the air temperature from GFS by $2{ }^{\circ} \mathrm{C}$ for every model time step. The relationship of the simulated SWE improved compared with SWE simulated with original GFS air temperature data (Fig. 11a and b). When the input air temperature increases from the GFS value, the snowmelt season 

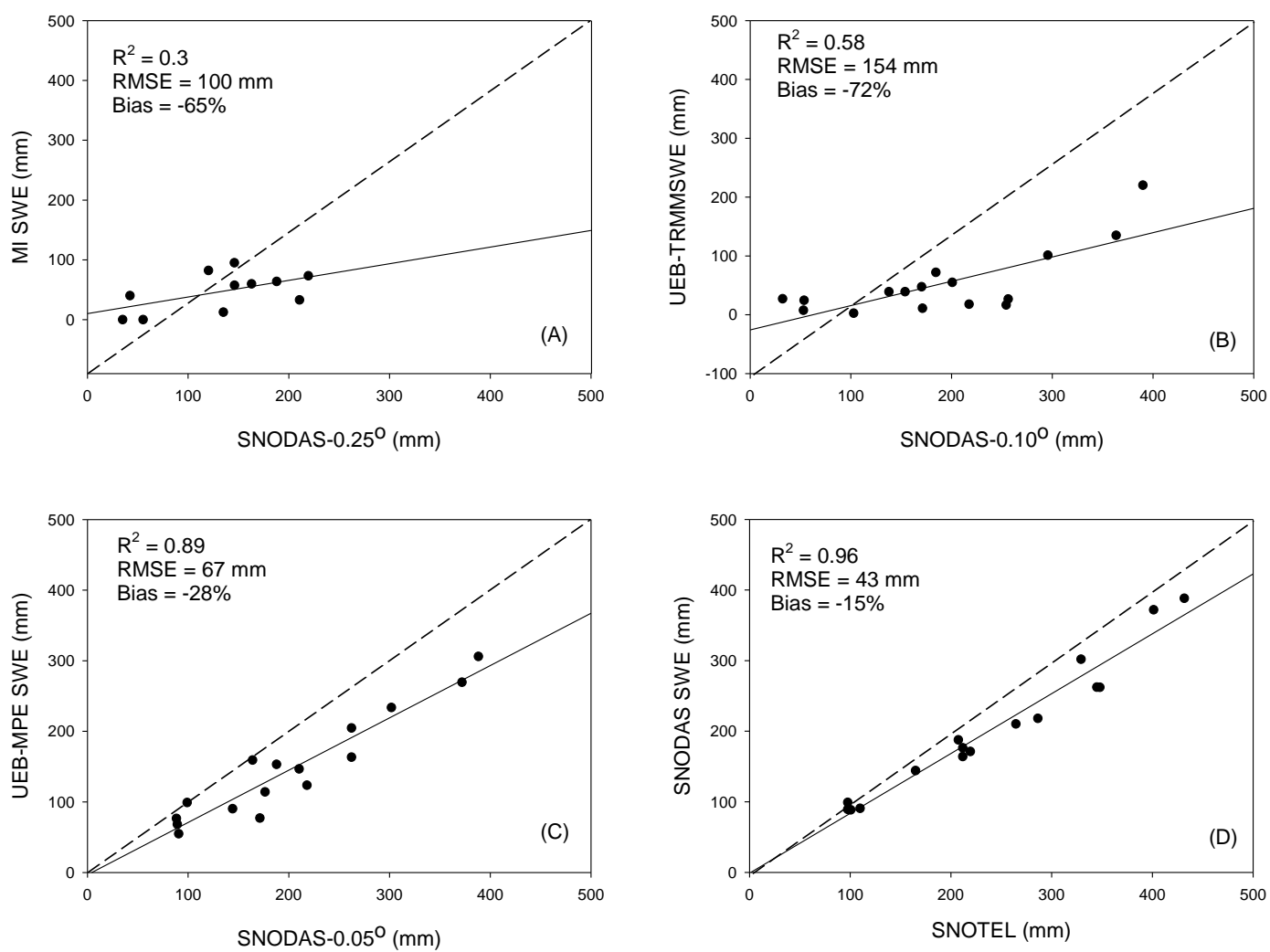

Fig. 10. Averaged SWE (at the 39 SNOTEL sites) from the SNODAS and the (A) SWE estimated from the microwave imagers for DecemberMay between January 2006 and April 2007; (B) SWE from the DisUEB with TRMM precipitation, and (C) DisUEB with MPE for January 2006-April 2008. (D) Average SWE of the SNODAS and SNOTEL data sets for the period January 2006-April 2008.
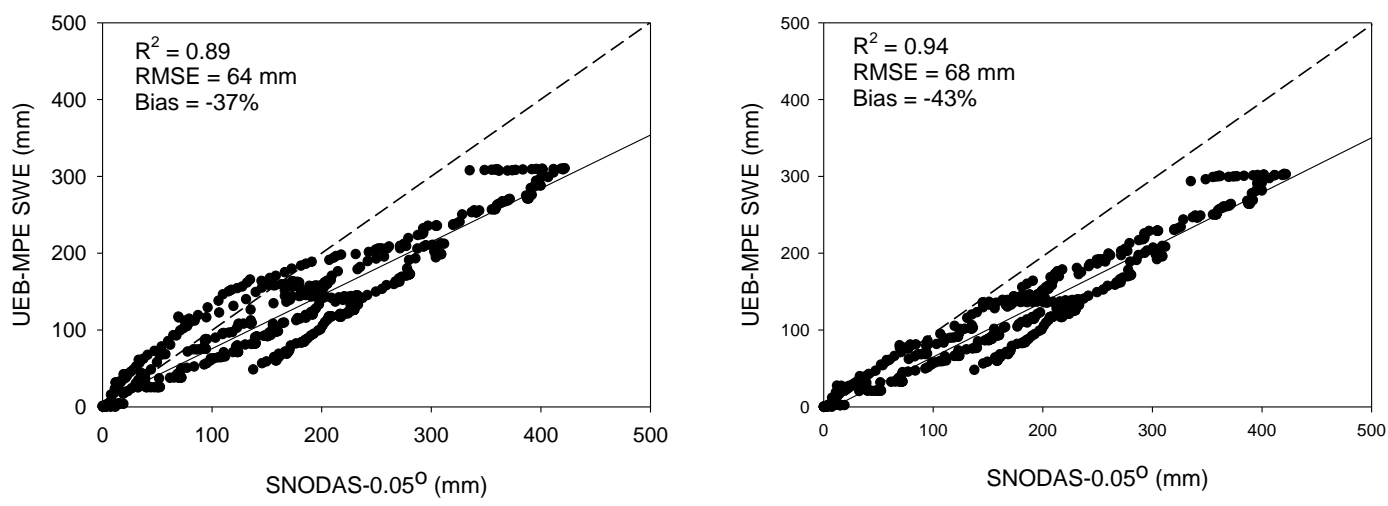

Fig. 11. Scatterplots of average daily SWE (at the 39 SNOTEL sites) from the SNODAS and the (A) SWE from simulated with UEB and MPE precipitation and the original GFS air temperature for January 2006-April 2008, and (B) SWE simulated with UEB and MPE precipitation and the original GFS air temperature increased by $2{ }^{\circ} \mathrm{C}$.

starts earlier and with a faster rate of melt, which improves the performance of the simulated SWE.

Most of the time, the UEB model underestimated SWE compared to the SWE values recorded at the SNOTEL stations and SNODAS. Our findings, on the underestimation of the simulated SWE, are consistent with the findings of other research on the underestimation biases of simulated SWE in the mountainous western US (Pan et al., 2003). The underestimation of the simulated SWE was consistent with the negative biases that MPE and TRMM precipitation data sets had when contrasted with SNOTEL precipitation recorded at a location inside the MPE or TRMM grid. Overall, the UEB-simulated SWE showed remarkable predictive skills compared to the SWE predicted by the SNODAS, and the 
agreement between the SNODAS- and SNOTEL-recorded SWE was marginal. Although the TRMM-simulated SWE had low quantitative skills to predict snow water content it nevertheless had good qualitative skills to predict snow water given the high correlation it exhibited when compared with SNODAS time series data. The better correlation between SWE simulated with UEB-TRMM and SWE from SNODAS and SNOTEL when time series basin-wide values were used is due to seasonality of the precipitation occurrence being captured by TRMM.

From a practical point of view, we found the MI-estimated SWE and SWE simulated from TRMM data sets to be unreliable sources for mapping SWE in the study area and to have a large underestimation bias compared with the SNOTEL SWE or the SWE estimated by the SNODAS system. Our results on the negative biases of the MI-estimated SWE are different from what Mote et al. (2003) reported. Mote et al. (2003) found that SWE estimated from SSM/I overpredicted during the melting period for five sites in the northern Great Plains.

\section{Conclusions}

We presented a distributed snow accumulation and ablation model that is built on the UEB model that uses data from weather forecast models as forcing input. Besides the weather forecast model (GFS) data, the snowmelt model was forced with two precipitation data sets: the NWS MPE and the TRMM precipitation estimates. The model was run at a 0.050 and $0.100^{\circ}$ resolution for the MPE and TRMM, respectively. We compared model-simulated SWE and MIestimated SWE with co-located SWE data sets recorded by the SNOTEL network or estimated by the SNODAS system. The SWE simulated by the UEB model was strongly correlated with the SWE estimated by SNODAS $\left(R^{2}=0.58\right.$ and $R^{2}=0.89$ for model input precipitation as TRMM and MPE, respectively) and the SWE recorded by SNOTEL $\left(R^{2}=0.46\right.$ and $R^{2}=0.87$ ) when the seasonal average SWE values were compared. The MI-estimated SWE was significantly correlated with the SNOTEL and not correlated with the SNODAS SWE product ( $R^{2}$ of 0.3 and 0.2 , respectively).

Both of the UEB-simulated and MI-estimated SWEs underestimated the SWE reported by the SNOTEL or SNODAS systems. The MI-estimated and the UEB-simulated SWE underestimated the SWE values seen in the SNOTEL and SNODAS data sets and lacked a discernable variability between sites seen in the SNOTEL and SNODAS SWE data and were found to be unreliable sources for mapping SWE in the study area. In the future, we will evaluate the effects of the parameterization of the snow albedo on the snowmelt processes by using remotely sensed snow albedo as input to the model. Notwithstanding their experimental nature, several snow albedo products with near-global coverage are now becoming available. Another area of future research is quantifying the propagations of uncertainty of the input meteorological data to the snow model output variables.

Acknowledgements. The authors would like to thank Gabriel Senay, Lei Ji, and Thomas Adamson for helpful comments on an early draft of the manuscript. We also would like to thank two anonymous referees for their constructive comments, which led to substantial improvements in the manuscript. The work of Guleid Artan was performed under USGS contract G13PC00028.

Edited by: A. Langousis

\section{References}

Armstrong, R. L., Brodzik, M. J., Knowles, K., and Savoie, M.: Global monthly EASE-Grid snow water equivalent climatology, National Snow and Ice Data Center, Digital media, Boulder, CO, 2007.

Artan, G. A., Neale, C. M. U., and Tarboton, D. G.: Characteristic length scale of input data in distributed models: Implications for modeling grid size, J. Hydrol., 227, 128-139, 2000.

Bales, R. C., Dressler, K. A., Imam, B., Fassnacht, S. R., and Lampkin, D.: Fractional snow cover in the Colorado and Rio Grande basins, 1995-2002, Water Resour. Res., 44, W01425, doi:10.1029/2006WR005377, 2008.

Blöschl, G.: Scaling issues in snow hydrology, Hydrol. Process., 13, 2149-2175, doi:10.1029/2006WR005377, 1999.

Carroll, S. S.: Modeling measurement errors when estimating snow water equivalent, J. Hydrol., 172, 247-260, 1995.

Chen, C. T., Nijssen, B., Guo, J., Tsang, L., Wood, A. W., Hwang, J. N., and Lettenmaier, D. P.: Passive microwave remote sensing of snow constrained by hydrological simulations, IEEE T. Geosci. Remote, 39, 1744-1756, 2001.

Cline, D. W., Bales, R. C., and Dozier, J.: Estimating the spatial distribution of snow in mountain basins using remote sensing and energy balance modeling, Water Resour. Res., 34, 1275-1285, 1998.

Daly, S. F., Davis, R., Ochs, E., and Pangburn, T.: An approach to spatially distrubuted snow modelling of the sacramento and San Joaquin basins, California, Hydrol. Process., 14, 3257-3271, 2000.

Dong, J., Walker, J. P., and Houser, P. R.: Factors affecting remotely sensed snow water equivalent uncertainty, Remote Sens. Environ., 97, 68-82, 2005.

Dozier, J. and Frew, J.: Rapid calculation of terrain parameters for radiation modeling from digital elevation data, IEEE T. Geosci. Remote, 28, 963-969, 1990.

Dressler, K. A., Leavesley, G. H., Bales, R. C., and Fassnacht, S. R.: Evaluation of gridded snow water equivalent and satellite snow cover products for mountain basins in a hydrologic model, Hydrol. Process., 20, 673-688, 2006.

Dubayah, R. and Van Katwijk, V.: The topographic distribution of annual incoming solar radiation in the Rio Grande River Basin, Geophys. Res. Lett., 19, 2231-2234, 1992.

Fassnacht, S. R.: Upper versus lower Colorado River sub-basin streamflow: Characteristics, runoff estimation and model simulation, Hydrol. Process., 20, 2187-2205, 2006. 
Habib, E., Larson, B. F., and Graschel, J.: Validation of NEXRAD multisensor precipitation estimates using an experimental dense rain gauge network in south Louisiana, J. Hydrol., 373, 463-478, 2009.

Janowiak, J. E., Joyce, R. J. and Yarosh, Y.: A real-time global halfhourly pixel-resolution infrared dataset and its applications, B. Am. Meteorol. Soc., 82, 205-217, 2001.

Josberger, E. G., Gloersen, P., Chang, A., and Rango, A.: The effects of snowpack grain size on satellite passive microwave observations from the Upper Colorado River Basin, J. Geophys. Res.-Oceans, 101, 6679-6688, 1996.

Joyce, R. J., Janowiak, J. E., Arkin, P. A., and Xie, P.: CMORPH: A method that produces global precipitation estimates from passive microwave and infrared data at high spatial and temporal resolution, J. Hydrometeorol., 5, 487-503, 2004.

Kelly, R. E., Chang, A. T., Tsang, L., and Foster, J. L.: A prototype AMSR-E global snow area and snow depth algorithm, IEEE T. Geosci. Remote, 41, 230-242, 2003.

Koivusalo, H. and Heikinheimo, M.: Surface energy exchange over a boreal snowpack: Comparison of two snow energy balance models, Hydrol. Process., 13, 2395-2408, 1999.

Molotch, N. P. and Bales, R. C.: Scaling snow observations from the point to the grid element: Implications for observation network design, Water Resour. Res., 41, 1-16, 2005.

Molotch, N. P. and Bales, R. C.: SNOTEL representativeness in the Rio Grande headwaters on the basis of physiographics and remotely sensed snow cover persistence, Hydrol. Process., 20, 723-739, 2006.

Mote, T. L., Grandstein, A. J., Leathers, D. J., and Robinson, D. A.: A comparison of modeled, remotely sensed, and measured snow water equivalent in the northern Great Plains, Water Resour. Res., 39, 1209, doi:10.1029/2002WR001782, 2003.

NOHRC - National Operational Hydrologic Remote Sensing Center: Snow Data Assimilation System (SNODAS) data products at NSIDC, National Snow and Ice Data Center, Boulder, Colorado, USA, 2004.

Pan, M., Sheffield, J., Wood, E. F., Mitchell, K. E., Houser, P. R., Schaake, J. C., Robock, A., Lohmann, D., Cosgrove, B., Duan, Q., Luo, L., Higgins, R. W., Pinker, R. T., and Tarpley, J. D.: Snow process modeling in the North American Land Data Assimilation System (NLDAS): 2. Evaluation of model simulated snow water equivalent, J. Geophys. Res.-Atmos., 108, 8850, doi:10.1029/2003JD003994, 2003.

Robinson, D. A. and Kukla, G.: Maximum surface albedo of seasonally snow-covered lands in the Northern Hemisphere, J. Clim. Appl. Meteorol., 24, 402-411, 1985.
Robinson, D. A., Dewey, K. F., and Heim Jr., R. R.: Global snow cover monitoring: an update, B. Am. Meteorol. Soc., 74, 16891696, 1993.

Schmugge, T. J., Kustas, W. P., Ritchie, J. C., Jackson, T. J., and Rango, A.: Remote sensing in hydrology, Adv. Water Resour., 25, 1367-1385, 2002.

Schulz, O. and de Jong, C.: Snowmelt and sublimation: field experiments and modelling in the High Atlas Mountains of Morocco, Hydrol. Earth Syst. Sci., 8, 1076-1089, doi:10.5194/hess8-1076-2004, 2004.

Serreze, M. C., Clark, M. P., Armstrong, R. L., McGinnis, D. A., and Pulwarty, R. S.: Characteristics of the western United States snowpack from snowpack telemetry (SNOTEL) data, Water Resour. Res., 35, 2145-2160, 1999.

Stone, P. and Carlson, J.: Atmospheric lapse rate regimes and their parameterization, J. Atmos. Sci., 36, 415-423, 1979.

Sun, C., Neale, C. M. U., and McDonnell, J. J.: Snow wetness estimates of vegetated terrain from satellite passive microwave data, Hydrol. Process., 10, 1619-1628, 1996.

Tarboton, D. G. and Luce, C. H.: Utah Energy Balance Snow Accumulation and Melt Model (UEB): Computer model technical description and users guide, Utah Water Research Laboratory and USDA Forest Service Intermountain Research Station, Logan, Utah, 64 pp., 1996.

Tekeli, A. E., Akyürek, Z., Şorman, A. A., Şensoy, A., and Şorman, A. Ü.: Using MODIS snow cover maps in modeling snowmelt runoff process in the eastern part of Turkey, Remote Sens. Environ., 97, 216-230, 2005.

Tian, Y., Peters-Lidard, C. , Choudhury, B., and Garcia, M.: Multitemporal analysis of TRMM-based satellite precipitation products for land data assimilation applications, J. Hydrometeorol., 8, 1165-1183, 2007.

Watson, F. G. R., Newman, W. B., Coughlan, J. C., and Garrott, R. A.: Testing a distributed snowpack simulation model against spatial observations, J. Hydrol., 328, 453-466, 2006.

Willmott, C. J.: Some comments on the evaluation of model performance, B. Am. Meteorol. Soc., 63, 1309-1313, 1982.

Wood, V. T., Brown, R. A., and Vasiloff, S. V.: Improved detection using negative elevation angles for mountaintop WSR-88Ds, Part II: Simulations of the three radars covering Utah, Weather Forecast., 18, 393-403, 2003.

Xie, P. and Arkin, P. A.: Global Precipitation: A 17-Year Monthly Analysis Based on Gauge Observations, Satellite Estimates, and Numerical Model Outputs, B. Am. Meteorol. Soc., 78, 25392558, 1997. 